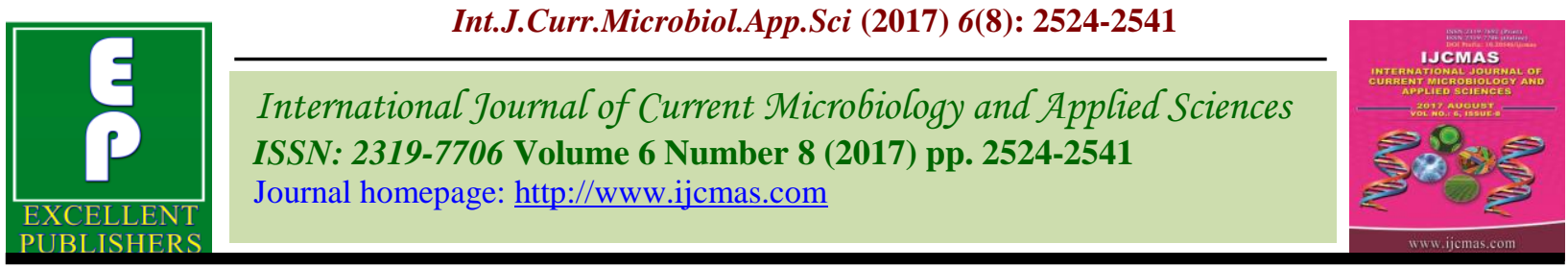

Original Research Article

https://doi.org/10.20546/ijcmas.2017.608.300

\title{
Phylogenetic and Antimicrobial Characteristics of a Novel Streptomyces sp. Ru87 Isolated from Egyptian Soil
}

\author{
Dina H. Amin ${ }^{1 *}$, Sahar Tolba ${ }^{1}$, Assem Abolmaaty ${ }^{2}$, \\ Nagwa A. Abdallah ${ }^{1}$ and Elizabeth M.H. Wellington ${ }^{3}$
}

\author{
${ }^{1}$ Department of Microbiology, Faculty of Science, Ain Shams University, Cairo, Egypt \\ ${ }^{2}$ Department of Food Science, Faculty of Agriculture, Ain Shams University, Cairo, Egypt \\ ${ }^{3}$ School of life Sciences, University of Warwick, Coventry, United Kingdom \\ *Corresponding author
}

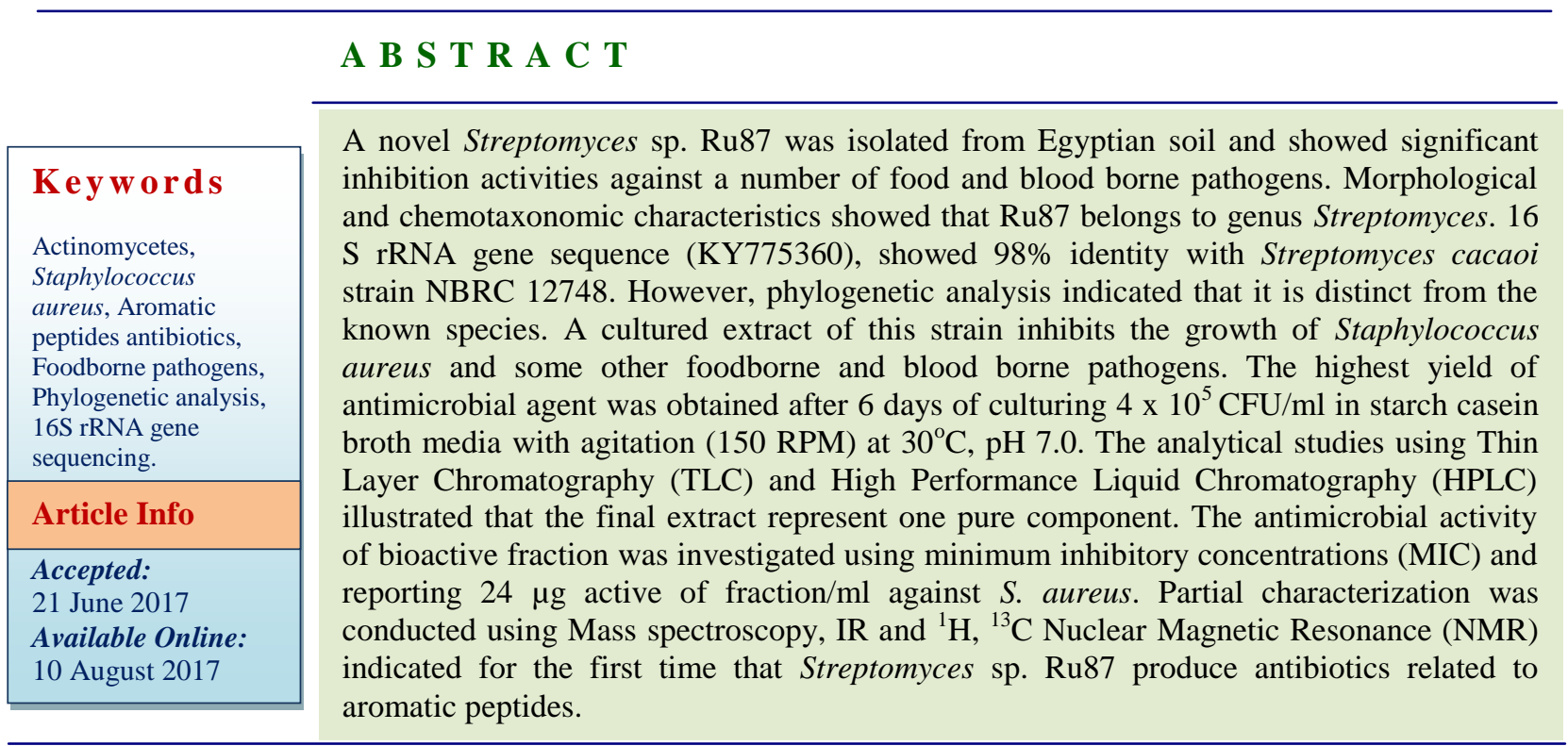

\section{Introduction}

Antimicrobial-resistant pathogens have been recognized as a major worldwide public health threat, causing morbidity, mortality and increasing healthcare costs (Pfaller et al., 1997, Hilal et al., 1997). It is of interest to mention that the common medicine penicillin for Staphylococcus aureus infection is extremely pronounced resistant (Roller, 1999) and nearly 500,000 patients are admitted to American hospitals annually due to staphylococcal infection (Korzeniowski and Sande, 1982). In Egypt, only few records on antimicrobial resistance were reported (El Kholy et al., 2003). Multi-drug-resistant Staphylococcus aureus has become overwhelming in Egyptian heath care sectors against oxacillin (Hassan et al., 2011), carbapenem (Falagas et al., 2013), methicillin (Laxminarayan et al., 2013) and erythromycin, co-trimoxazole, clindamycin and doxycycline (El-Kholy et al., 2003). S. aureus has been recognized as major foodborne pathogens, leading to a wide variety of illnesses, as well as life-threatening 
diseases, such as pneumonia, meningitis, bacteremia, osteomyelitis, endocarditis, toxic shock syndrome (TSS), and sepsis (Korzeniowski and Sande, 1982).

Genus Streptomyces has been recognized as the main genus of Actinomycetes in Streptomycetaceae exploring over than 500 species (Euzeby, 2008). Over the years, there has been an increasing interest toward the isolation of Streptomyces species as a great source of bioactive metabolites (Mellouli et al., 2003)and its utilizations in medical and agriculture applications (Watve et al., 2001).

Genus Streptomycesis a genus of Grampositive bacteria that grows in different environments with complex secondary metabolic pathways (Madigan and Martino, 2005). Streptomyces species produce about 75 $\%$ of commercially and medically useful antibiotics (Miyadoh, 1993)such as neomycin, cypemycin, grisemycin, bottromycins, and chloramphenicol) (Kieser et al., 2000).The identification of actinomycetes via traditional methods such as phenotypic characteristics is not as accurate as genotypic methods. 16S rRNA gene sequence analysis has been recognized as a powerful tool for the identification of poorly described, rarely isolated, or phenotypically aberrant strains, and can lead to unique phylogenetic analysis of the newly isolated strain to the genus Streptomyces (Heuer et al., 1997 and Monciardini et al., 2002).

\section{Materials and Methods}

\section{Microorganism and routine cultivation}

Ru87 new strain was isolated from Egyptian soilas follows: Soil sample was subjected to sucrose gradient centrifugation treatment (Yamamura et al., 2005) and then serial dilutions were made from the supernatant. A 0.1-ml inoculum of each serial dilution was cultured in starch casein and humic acid vitamin agar plates (Hayakawa and Nonomura, 1987) for 20 days at $30^{\circ} \mathrm{C}$.Colonies were carefully picked up and cultivated on starch casein agarcontained cycloheximide (50 $\mathrm{mg} \mathrm{l}^{-1}$ ) as an antifungal agent (Williams and Davies, 1965).

Isolate Ru87 wasroutinely cultivated according to (Abbas and Edwards, 1990) with some modifications: spore suspension was cultivated into $35 \mathrm{ml}$ of starch casein broth media for 8 days at $30^{\circ} \mathrm{C}$. The incubation was conducted either statically or by shaking at 150 RPM. The final spore suspension was lypholized at the Mycological center, Assiut University, Assiut, Egypt and then kept at $20^{\circ} \mathrm{C}$ for future use. Test bacteria, including Food and blood borne pathogens (Staphylococcus aureus ATCC 6538, Pseudomonas aeruginosa ATCC 10145, Klebsiella pneumonia CCM 4415, Streptococcus mutans ATCC 25175, Escherichia coliO157:H7 ATCC 51659 and Salmonella enterica ATCC 25566) were obtained as a gift from Ain shams Specialized Hospital and the Microbial Resources Center (MIRCEN) at the Faculty of Agriculture, Ain shams university, Cairo, Egypt. Routine Cultivation of these strains was conducted overnight in nutrient broth at $37^{\circ} \mathrm{C}$.

\section{Agar well diffusion method}

Agar well diffusion method was conducted with Ru87 against bacterial pathogens as a preliminary screening of its antimicrobial activities. Actinomycetes spore suspensions were prepared as stated above. Cell-free supernatant $(250 \mu \mathrm{l})$ was added in each well in nutrient agar Petridishes containing $0.5 \mathrm{Mcfarland}$ of tested bacterial spores (McFarland, 1907). Petridishes were then incubated for $24 \mathrm{hrs}$ at $37^{\circ} \mathrm{C}$. Results were recorded by measuring the inhibition zone areas (Cooper, 1972). All tests and 
experiments were made in duplicates. Potent isolate was subjected to further study.

\section{Morphological and chemotaxonomic analysis}

The preliminary identification of isolates was carried out for morphological and chemotaxonomic characterization. Identification of Ru87 was carried out according to Bergey's Manual of systematic Bacteriology, Vol. 4 (Locci, 1989). The morphological characteristics of the organism investigated aerial, substrate mycelium and spore formation. Observation was examined by naked eyes examination after 8 days of culturing isolate $\mathrm{Ru} 87$ at $30^{\circ} \mathrm{C}$ in different media; glycerol arginine agar, soya bean agar, oatmeal agar, glucose- yeast extract agar, czapeks agar, nutrient agar and starch casein agar (Shirling and Gottlieb,1966). Slide culture technique was conducted as follows: sterilized glass slides were inserted diagonally at the center of a petridish containing thick layer of starch casein agar at an angle $45^{\circ}$. Then, Ru87 was inoculated once at the inner interface between the slide and media in one direction. Petridishes were incubated for 6,8 days at $30^{\circ} \mathrm{C}$ (Williams et al., 1989) and the growth of aerial mycelium and examined under light microscopy, Labo, USA. Chemotaxonomic characterization of Diaminopimelic acid (DAP) isomers in the cell wall hydrolysate was examined as follows: Ru87 biomass was obtained from 8 days culture grown in starch casein broth medium in shaking incubator (150 RPM) at $30^{\circ} \mathrm{C}$. Cells were harvested by filtration using filter paper (Whatman) and allowed to dry. Dried cells ( $3 \mathrm{mg}$ ) were mixed with $1 \mathrm{ml}$ of 6 $\mathrm{N} \mathrm{HCl}$ in clean Eppendorf tubes. After one hour in the autoclave at $121{ }^{\circ} \mathrm{C}, 3 \mu \mathrm{l}$ of each sample was added to cellulose paper chromatogram (whatman) loaded with $1 \mu$ of 0.01 M DL-DAP (Sigma). Cellulose paper chromatogram was placed in a closed glass container containing " $\mathrm{MeOH}: \mathrm{H}_{2} \mathrm{O}$ : $6 \mathrm{~N} \mathrm{HCl}$ : Pyridine at a ratio (80:26:4:10, v/v)" and then left for $3 \mathrm{hrs}$ to allow the mobile phase solvents to interact with the stationary phase. Spots were obviously visualized after spraying the chromatogram with $0.2 \%$ ninhydrin in water-saturated n-butanol follow by drying in the oven at $100{ }^{\circ} \mathrm{C}$ for $5 \mathrm{~min}$ (Staneck and Roberts, 1974).

\section{S-rRNA genes amplification}

Extraction of genomic DNA was conducted using promega Wizard $\AA$ Genomic DNA Purification Kit. PCR analysis of $16 S$ rRNA gene was performed as described by (Hopwood et al., 1985). Universal Primers pairs PA

$(5$ 'AGAGTTTGATCCTGGCTCAG-3')

(Edwards et al., 1989) and 517R (5'ATTACCGCGGCTGCTGG-3' (Heuer et al., 1997) were used to amplify $500 \mathrm{bp}$. PCR was performed using thermal cycler (Applied biosystem 337). PCR conditions were adjusted to $5 \mathrm{~min}$ for initial denaturation at $94^{\circ} \mathrm{C}$ and then 35 cycles of $1 \mathrm{~min}$ at $94^{\circ} \mathrm{C}, 1$ $\min$ at $54^{\circ} \mathrm{C}$, and $1 \mathrm{~min}$ at $72^{\circ} \mathrm{C}$, and finally $10 \mathrm{~min}$ at $72^{\circ} \mathrm{C}$.A tube served as a negative control was performed, containing all components of the mixture and water instead of DNA template. Negative control and PCR products were subjected to electrophoresis for $30 \mathrm{~min}$ at 90 Volt in $1 \%$ agarose gels stained with $50 \mathrm{mg} / \mathrm{ml}$ of ethidium bromide. Electrophoresis running buffer consisted of $0.2 \mathrm{MTris}$ base, $0.1 \mathrm{Msodium}$ acetate, and 0.01 $\mathrm{M} \mathrm{Na} \mathrm{N}_{2}$ EDTA, at $\mathrm{pH}$ 7.8. Digital images were obtained using a UV transilluminator (BioRad Laboratories, Hercules, CA).

Gene sequencing and phylogenetic analysis

PCR Amplicons of16S-rRNA genes were sequenced using (DYEynamic ET Terminator Cycle Sequencing Kit, Amersham Pharmacia Biotech.), and genetic sequence analyser (ABI 
3130) at the Animal Health Research Institute, El Dokki, Egypt. The 16S rDNA sequences were deposited and used to search the nucleotide blast algorithm at the GenBank database (http://blast.ncbi.nlm.nih.gov/). Multiple sequences were aligned using the CLUSTAL W program (Thompson et al., 1994) against corresponding nucleotide sequences. This would display the closest matches to $16 \mathrm{~S}$ rDNA sequences for identifying known species. Sequence analysis and phylogenetic tree construction was then conducted using the Molecular Evolutionary Genetics Analysis (MEGA) software version 7 (Tamura et al., 2011). Partial 16S rRNA gene sequences of isolate Ru87 was compared with other 16S rRNA sequences of valid microbial strains published in NCBI database at (https://blast.ncbi.nlm.nih.gov).

\section{Optimization of growth conditions}

Varying growth factors would inevitably have great impacts on the yield of antibiotics produced by actinomycetes (Waksman and Schatz, 1945). Growth condition of isolate Ru87 was optimized by varying the following growth factors: incubation periods, initial $\mathrm{pH}$, and different sources of carbon and nitrogen (Egorov, 1985). This would eventually lead to maximize the yield of antimicrobial biosynthesis. To determine the optimum incubation period, starch casein brothmedia $(35 \mathrm{ml})$ was inoculated with $1 \mathrm{ml}$ spore suspension of 8-days grown culture of Ru87 and subjected to various incubation periods $(2$, $4,6,8,10$ and 12 days) in shaking incubator $(150 \mathrm{RPM})$ at $30^{\circ} \mathrm{C}$. In order to reach the optimum $\mathrm{pH}$, initial $\mathrm{pH}$ of the starch casein broth was varied $(4,5,6,7,8$ and $9 \mathrm{pH}$ values) using $0.1 \mathrm{M} \mathrm{NaOH}$ or $0.1 \mathrm{M} \mathrm{HC1}$ for adjustments. Flasks were then inoculated with $1 \mathrm{ml}$ spore suspension of 8-days grown culture of Ru87 and incubated for 8 days (150 $\mathrm{RPM})$ at $30^{\circ} \mathrm{C}$. The ability of isolate Ru87 to use different sole carbon and nitrogen sources was also investigated. Carbon sources (Dglucose, D-fructose, sucrose, D-mannitol, lactose, maltose, starch and molasses) and nitrogen sources (ammonium nitrate, ammonium persulphate, casein, yeast extract, peptone, malt and soyabean meal) were replaced in starch casein broth media by the value $1 \%(\mathrm{w} / \mathrm{v})$. One milliliter of spore suspension of 8-days grown culture of Ru87 was inoculated in each flask and incubated for 8-days $(150 \mathrm{RPM})$ at $30^{\circ} \mathrm{C}$. Antimicrobial activities assessments of optimization procedures were conducted via Agar well diffusion method. Cell free supernatant of each flask was tested against $S$. aureus using agar well diffusion method as previously stated (Cooper, 1972). One milliliter of spore suspension of isolate Ru87 (equivalent to $4 \mathrm{x}$ $10^{5} \mathrm{CFU} / \mathrm{ml}$ ) found to produce maximum yields of antimicrobial agent, and therefore was used in all experiments (Abdelwahed et al., 2012).

\section{Isolation and purification of antimicrobial products}

A total volume of $500 \mathrm{ml}$ starch casein broth media were inoculated with spore suspensions (1\%) of isolate Ru87. The fermentation process was carried out for 8 days at $30^{\circ} \mathrm{C}$ under shaking conditions (150 RPM). Cellfree supernatant of isolate Ru87 was obtained by filtration through filter paper (Whatman). The cell-free supernatant was tested for its antimicrobial activity against $S$. aureus by agar well diffusion method as previously stated.Cell-free supernatant $(500 \mathrm{ml})$ of $\mathrm{Ru} 87$ isolate, containing the active metabolites was extracted using chloroform-ethylacetate (1:1 $\mathrm{v} / \mathrm{v}$ ) in a separating funnel. After three times extraction, the organic and aqueous layers were tested against the $S$. aureus by agar well diffusion method as previously described. The mixture was then evaporated at $37^{\circ} \mathrm{C}$ in a rotatory evaporator under vacuum until dry. The crude residue was dissolved in $3 \mathrm{ml}$ of 
ethyl acetate for future use. The crude was then purified by loading $5.0 \mu \mathrm{l}$ on aluminum silica gel Thin Layer Chromatography plate (TLC) with a dimension of $(20 \times 20 \mathrm{~cm}$, Merck). TLC plates were placed in a closed glass jar containing chloroform and methanol solvents at a ratio $(4: 1 \mathrm{v} / \mathrm{v})$ for $3 \mathrm{hrs}$ at $30^{\circ} \mathrm{C}$. The active substances were revealed on silica gel TLC plates and retention factor (RF) value was measured. Each fraction was scratched, eluted in $50 \mu \mathrm{l}$ DMSO and antimicrobial activity was assessed again with agar well diffusion method against $S$. aureus ATCC 6538. Control Wells were filled with DMSO solution and served as control.

\section{Physico-chemical characteristics of antimicrobial compounds}

The brown fraction obtained by thin layer chromatography was scratched, eluted in DMSO and subjected to Liquid Chromatography-Mass Spectrometry (LCMS) conducted in the Selected Ion Monitoring (SIR) mode and High Performance Liquid Chromatography (HPLC) conducted in the Multiple Reaction Monitoring (MRM) mode at AGERI center, Cairo, Egypt.

The mass spectrum of the active molecules in methanol was determined by using mass spectrophotometer API 2000 (PE Sciex Applied Bio systems, Foster City, CA, USA) at the Central Laboratory Services, National Research Centre in Cairo, Egypt. Additional measures were also performed: Infrared spectra (IR) of the active molecule recorded in DMSO using potassium bromide disks with Perkin-Elmer Infrared 127B Spectrophotometer (Tiwari and Gupta, 2012). ${ }^{1} \mathrm{H},{ }^{13} \mathrm{C}$ Nuclear Magnetic Resonance (NMR) analysis (Berdy, 2012) of pure fraction was recorded on a Varian $500 \mathrm{MHZ}$ NMR spectrometer with tetra-methyl silane (TMS) as an internal standard, in
Microbiology laboratory, Cairo University, Egypt.

\section{Minimum Inhibitory Concentration (MIC)}

The Minimum inhibitory concentration (MIC) was detected using tube Dilution Assay (Wiegand et al., 2008). Different concentrations of purified active fraction eluted in DMSO $(0.3,0.6,0.9,1.5,3,6,12$ and 24$) \mu \mathrm{g} / \mathrm{ml}$ were each added to $5 \mathrm{ml}$ nutrient broth tubes, vortexed and then inoculated with equal amount $(10 \mu \mathrm{l})$ of overnight culture of $S$. aureus ATCC6538 ( $\mathrm{A}_{600}$ of 0.164 ). Tubes were incubated at $37^{\circ} \mathrm{C}$ for $24 \mathrm{hrs}$ and then $\mathrm{A}_{600}$ was measured by spectrophotometer. The Minimum inhibitory concentration (MIC) was identified as the first concentration that appears to inhibit bacterial growth.

\section{Results and Discussion}

\section{Potential antimicrobial activities of isolate Ru87}

Preliminary screening of Ru87 isolate showed pronounced antimicrobial activities against tested bacteria including Gram positive (Staphylococcus aureus and Streptococcus mutans) and Gram negative bacteria (Pseudomonas aeruginosa, and Escherichia coli). Antimicrobial activities were not noticeable with Klebsiella pneumonia and Salmonella enterica.

\section{Morphological and chemotaxonomic characterization}

Powdery texture was clearly observed (Table 1) after 8 days of cultivating Ru87 isolate at $30^{\circ} \mathrm{C}$ in 7 different media (glycerol arginine agar, soya bean agar, oatmeal agar, glucoseyeast extract agar, czapeks agar, nutrient agar and starch casein agar). Color series of aerial mycelium was varied (Table 1) among 
different culture media; it was whitish brown (glycerol arginine agar, oatmeal agar, czapeks agar, and starch casein agar), white (soya bean agar, glucose- yeast extract agar, and nutrient agar), and whitish grey (oatmeal agar). Substrate mycelium color ranged from pale brown to dark brown with the above mentioned media as shown in table 1.

A brown soluble pigment was only detected with starch casein agar. The morphological properties on starch casein agar indicated that Ru87belongs to genus Streptomyces in Family Streptomycetaceae based on the following observations: powdery colonies, whitish grey aerial mycelium and brown substrate mycelium (Fig. 1A). Moreover, spore chains were observed on aerial mycelium only with both curved and hook shaped as shown in (Fig. 1B). Chemotaxonomic analysis indicated that isolate Ru87 contained LL, Diaminopimilic acid in the cell wall.

\section{Molecular characterization}

PCR amplification of 16S rRNA genes (gamma region) was performed for genotyping identification of Ru87. Digital images of agarose gel captured by UV transilluminator (Bio-Rad Laboratories, Hercules, CA) confirmed the amplification of 500-bp fragments of $16 \mathrm{~S}$ rRNA gene with by PA and 517R primers (Fig. 2).

16S rRNA genes sequence analysis and phylogenetic tree

The universal PCR offer a great advantage for the identification of actinomycetes (Provost et al., 1997). Amplicons resulting from primer pairs PA and R517 were selected for the identification of the Ru87 isolate. The genus Streptomyces was found to be the predominant identified bacteria when sequences were blasted with nucleotide database using a nucleotide query algorithm.
The partial 16S rRNA gene sequence is already deposited in Genbank under the accession number KY775360.

AAGATGAAGCCCTTCGTAATAGGATTA GTGGCGAACGGGTGAGTAACACGTGG GCAATCTGCCCTGCACTCTGGGACAAG CCCTGGAAACGGGGTCTAATACCGGAT ACGACCACCGGCCGCATGGTCTGGTGG TGGAAAGCTCCGGCGGTGCAGGATGA GCCCGCGGCCTATCAGCTTGTTGGTGG GGTGATGGCCTACCAAGGCGACGACG GGTAGCCGGCCTGAGAGGGCGACCGG CCACACTGGGACTGAGACACGGCCCA GACTCCTACGGGAGGCAGCAGTGGGG AATATTGCACAATGGGCGAAAGCCTG ATGCAGCGACGCCCCTGAGGGATGAC GGCCTTCGGGTTGTAAACCTCTTTCAG CAGGGAAGAAGCGTGAGTGACGGTAC CTGCAGAAGAAGCACCGGCTAACTAC GTGCCAGCAGCGGGGGTAATATG.

A comprehensive analysis of $16 \mathrm{~S}$ rRNA Streptomyces gene tree was conducted in order to clarify the relationship between Ru87 isolate and closely related Streptomyces species. The 16S rRNA gene sequence of the strain Ru87 was compared with the nucleotide sequences of other Streptomyces strains from the NCBI GenBank database. The phylogenetic tree was generated base on the comparison between 16S rRNA gene sequence of the strain Ru87 and other nucleotide sequences from closely related Streptomyces strains using neighbor-joining method. NJ phylogenetic tree was divided into 2 large clades.

Isolate Ru87 was grouped with Streptomyces cacaoi strain NBRC 12748 and Streptomyces violaceoruber strain CSSSP679with alow bootstrap $(42 \%)$ and $(26 \%)$ respectively as shown in (Fig. 3). It is of interest to note that 500 bp of the Ru87 sequences below were highly aligned (98\%) when they were tested according to BLASTn, nucleotide alignment (bl2seq), this 98\% identity shows that PCR 
product was almost fully sequenced. Based on morphological, chemotaxonomic and analysis of the 16S rRNA gene sequence, the bacteria isolated from Egyptian soil were identified as Streptomyces sp. Ru87.

\section{Optimization of growth condition}

Highest yield of antimicrobial agent was obtained as a result of varying a number of growth variables. Different variables were studied at the following order: $\mathrm{pH}$ value, incubation period, carbon source and nitrogen source. Varying $\mathrm{pH}$ values of 8-days culture confirmed that $\mathrm{pH} 7$ generated the highest inhibition zoning $(2.5 \mathrm{~mm})$ of antimicrobial substances when tested against $S$. aureus using agar well diffusion method (Fig. 4A). Values of $\mathrm{pH}$ ranged from 4 -6 did not produce any noticeable antibiotics. The incubation periods of culturing Ru87 isolate showed that 6-days of incubation is the optimum (Fig. 4B). A proportional relationship was recorded with ascending pattern between 2-6 days of incubation, and then dramatically declined. It is of interest to notice that 12-days culture did not show any antimicrobial activates against $S$. aureus.

The use of different carbon sources produced different levels of antimicrobial agent at the following order: starch with $(2.5 \mathrm{~mm})$ inhibition zone diameter, followed by mannitol and lactose (Fig. 5). No antimicrobial substance was detected using maltose, sucrose, fructose and molases. During this study casein was the most favorable nitrogen source for the antimicrobial productivity $(2.5 \mathrm{~mm})$ diameter. Other organic nitrogen source such as malt, peptone, ammonium nitrate, ammonium sulfate, soya bean meal and yeast extract recorded very low antimicrobial substance production as shown in (Fig. 5).

Table.1 The morphological characteristics of isolate Ru87. Observation of aerial, substrate mycelium and soluble pigments was examined by naked eyes after 8 days of culturing isolate $\mathrm{Ru} 87$ at $30^{\circ} \mathrm{C}$ on different types of media; glycerol arginine agar, soya bean agar, oatmeal agar, glucose- yeast extract agar, czapeks agar, nutrient agar and starch casein agar

\begin{tabular}{|c|c|c|c|c|}
\hline \multirow[b]{2}{*}{ Culture media } & \multicolumn{4}{|c|}{ Ru87 } \\
\hline & Texture & $\begin{array}{c}\text { Aerial } \\
\text { mycelium }\end{array}$ & $\begin{array}{l}\text { Substrate } \\
\text { mycelium }\end{array}$ & $\begin{array}{l}\text { Soluble } \\
\text { pigment }\end{array}$ \\
\hline $\begin{array}{c}\text { Glycerol } \\
\text { arginine agar }\end{array}$ & powdery & Whitish brown & Dark Brown & none \\
\hline Soya bean agar & powdery & White & Pale Brown & none \\
\hline Oat meal agar & powdery & Whitish grey & Brown & none \\
\hline $\begin{array}{c}\text { Glucose- yeast } \\
\text { extract agar }\end{array}$ & powdery & White & Brown & none \\
\hline Czapeks agar & powdery & Whitish brown & Brown & none \\
\hline Nutrient agar & powdery & White & Pale Brown & none \\
\hline $\begin{array}{c}\text { Starch casein } \\
\text { agar }\end{array}$ & powdery & Whitish brown & Brown & Pale Brown \\
\hline
\end{tabular}


Fig.1 Morphological identification of isolate Ru87. (A) Macroscopic characteristics of isolate Ru87, (B) Microscopic examination of isolate Ru87 using Slide culture technique. Slide culture technique was conducted using sterilized glass slide in petridish containing thick layer of starch casein agar. Then, Ru87 was inoculated and petridishes are kept in the incubator for 6, 8 days at

300C. After incubation period, the growth of aerial mycelium and examined under light microscopy, Labo, USA
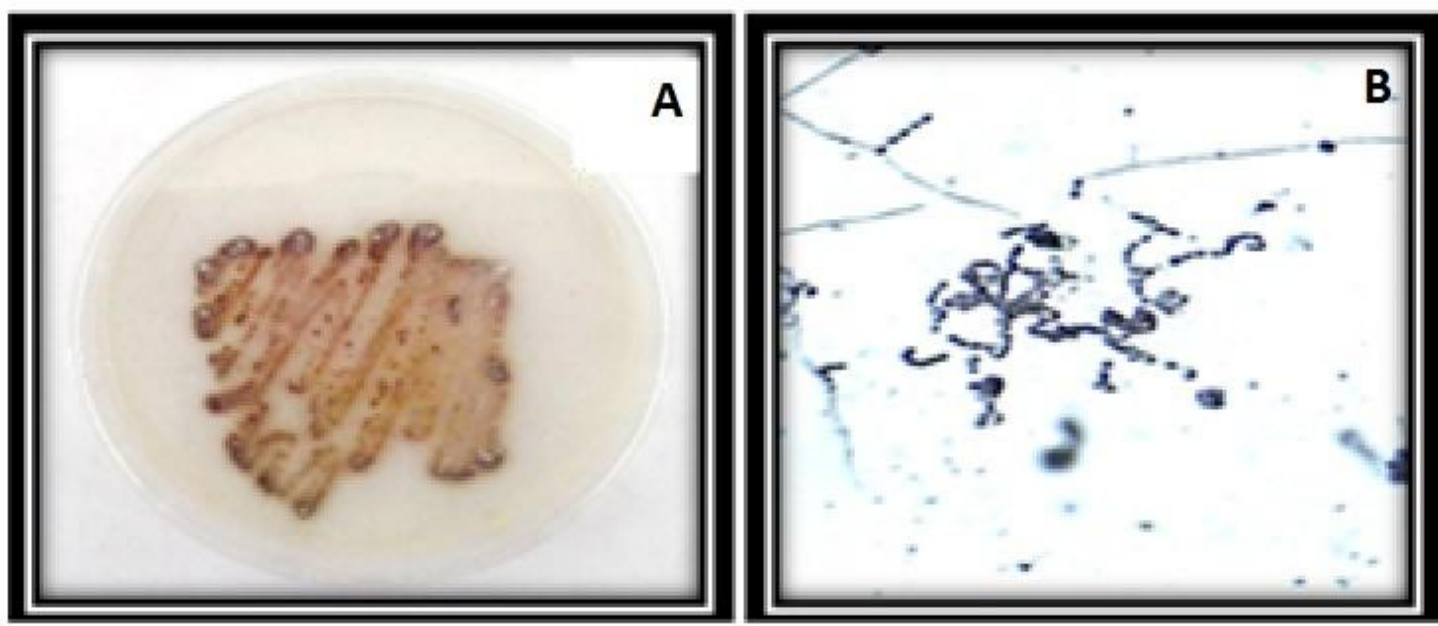

Fig.2 Gel electrophoresis of agarose gel illustrating the amplification of partial 16SrRNA genes of isolate Ru87 PCR amplicons of 16SrRNA genes using PA and R517 primers were subjected

to electrophoresis in $1 \%$ agarose gels with $50 \mathrm{mg} / \mathrm{ml}$ of ethidium bromide. Electrophoresis running buffer (0.2MTris base, 0.1Msodium acetate, and 0.01 M Na2EDTA, pH 7.8) for 30 min at $90 \mathrm{~V}$. Digital images were obtained using a UV transilluminator (Bio-Rad Laboratories, Hercules, CA). Lanes; M: 1kbp DNA ladder, 1-2: Negative control, 3-6: Amplified partial 16S rDNA (500 bp)

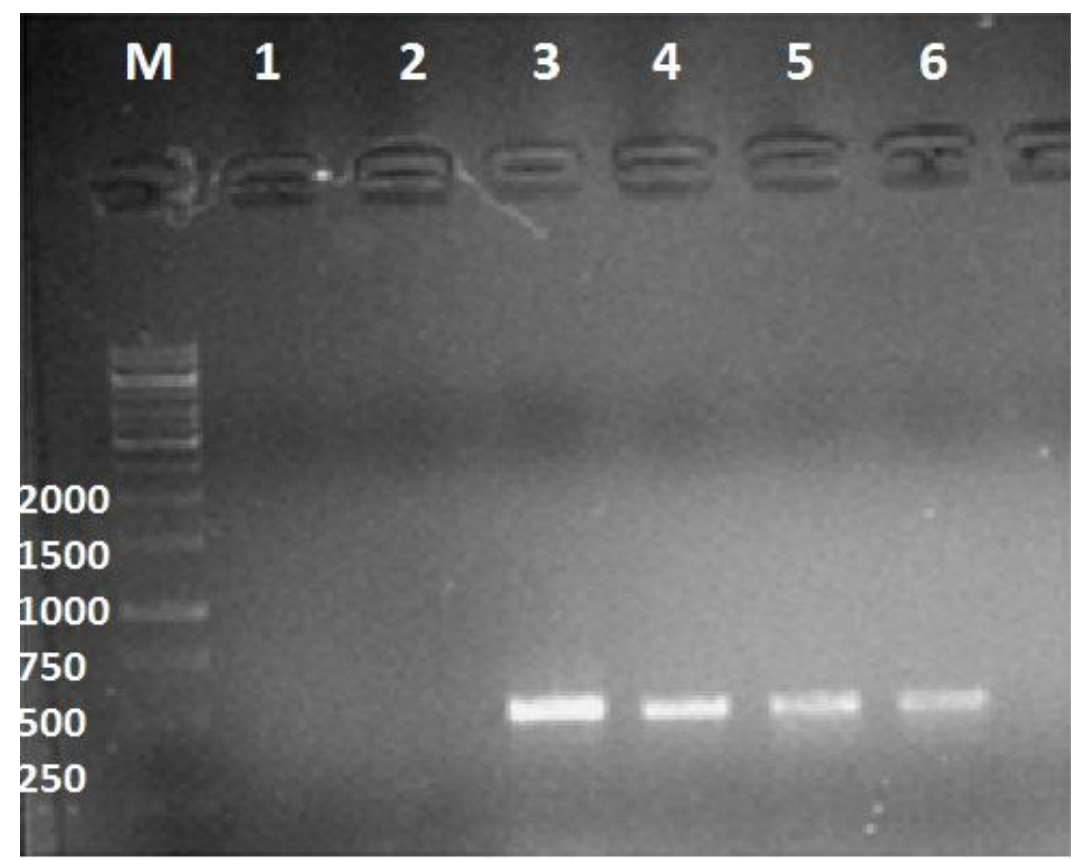


Fig.3 Phylogenetic tree based on 16S rRNA gene sequences from the strain Ru87 and other Streptomyces species.Multiple sequences were aligned using the CLUSTAL W program (Thompson et al., 1994) against corresponding nucleotide sequences. The tree was constructed using the neighbour-joining method using the Molecular Evolutionary Genetics Analysis (MEGA) software version 7 (Tamura et al., 2011). The numbers besides the branches indicate the percentage bootstrap value of 1000 replicates. The scale bar indicates nucleotide sequence dissimilarity

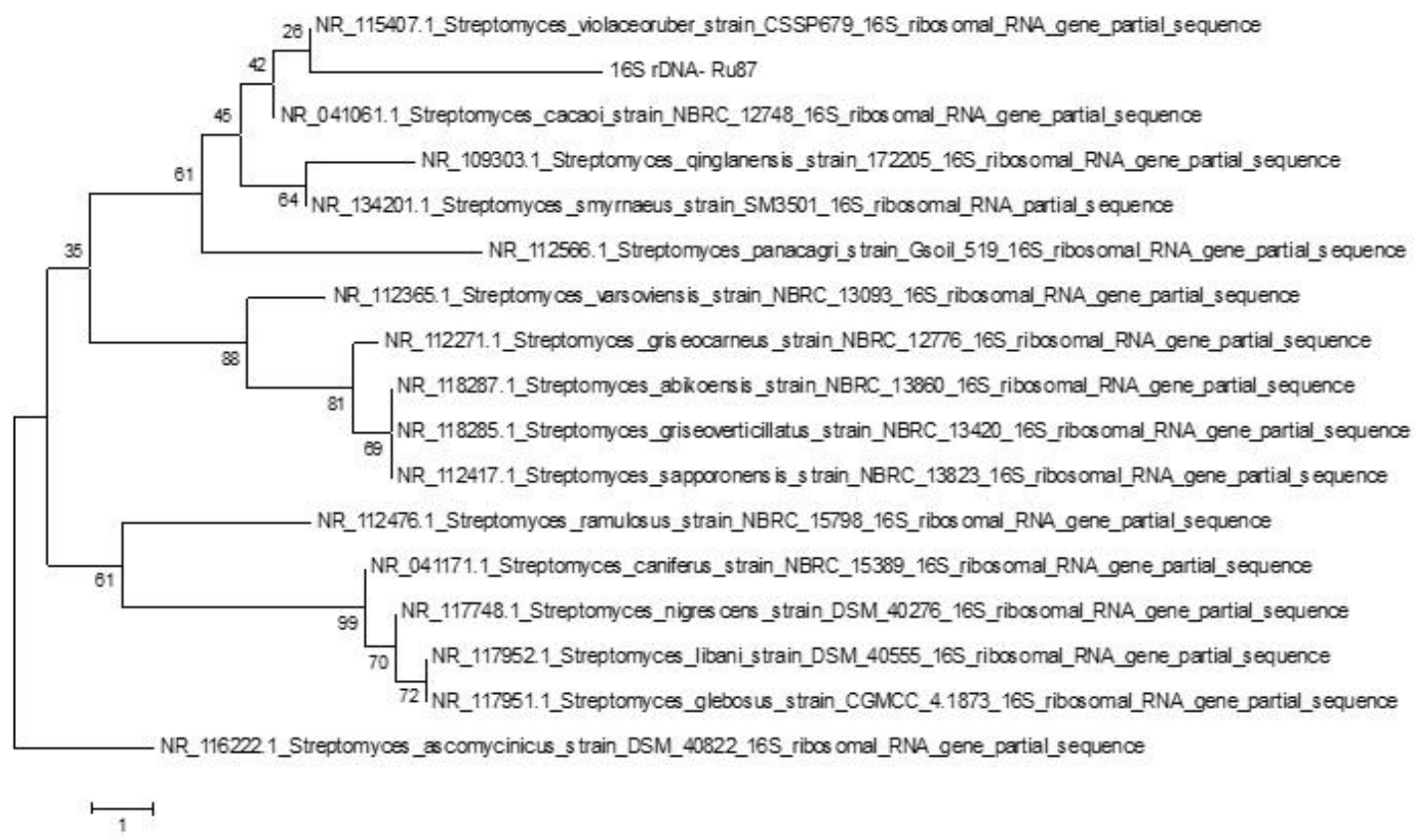

Fig.4 Effects of incubation time and $\mathrm{pH}$ values on antimicrobial activities of isolate Ru87 against $S$. aureus. Varying initial $\mathrm{pH}$ values of the starch casein broth $(35 \mathrm{ml})$ was adjusted ranging from 4 to $9 \mathrm{pH}$ value, flasks were inoculated with $1 \mathrm{ml}$ spore suspension of 8-days grown culture of Ru87 and incubated for 8-days (150 RPM) at 300C. Various incubation periods $(2,4,6,8,10$ and 12 days) were also selected in shaking incubator (150 RPM) at $30^{\circ} \mathrm{C}$. After incubation, 0.25 $\mathrm{ml}$ of cell free supernatant of each flask was tested against $S$. aureus by agar well diffusion method
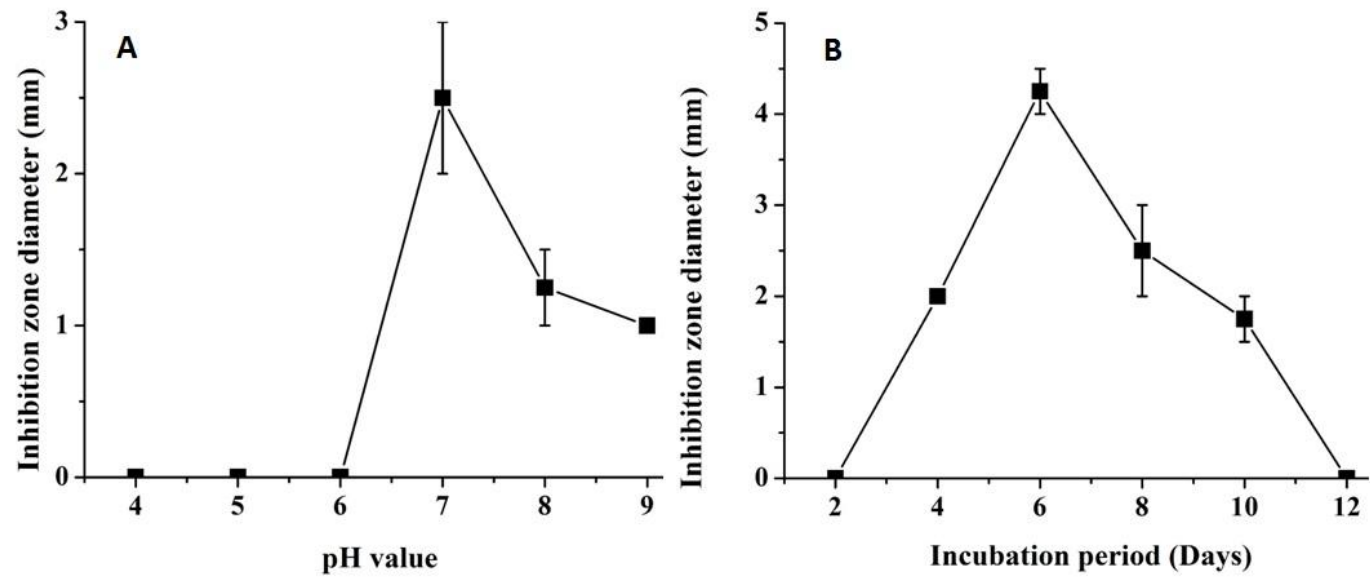
Fig.5 Effects of different sources of carbon and nitrogen on antimicrobial activities of isolate Ru87 against S. aureus. Different Carbon sources (C. a: Glucose, C. b: Lactose, C. c: Maltose, C. d: Sucrose, C. e: Fructose, C. f: Mannitol, C. g: Starch, C. h: Molasses), and Nitrogen sources (N. a: Peptone, N. b: Malt, N. c: Yeast extract, N. d: Ammonium nitrate, N. e: Ammonium sulfate, N. f: Casein, N. g: Soyabean meal) were investigated. Each of these above mentoned component was replaced in starch casein broth media by the value $1 \%(\mathrm{w} / \mathrm{v})$, inoculated with 1.0 $\mathrm{ml}$ of spore suspensions of 8-days grown culture of Ru87 and incubated for 8-days (150 RPM) at 300C. Finally, $0.25 \mathrm{ml}$ of cell free supernatant was tested against $S$. aureus by agar well diffusion method

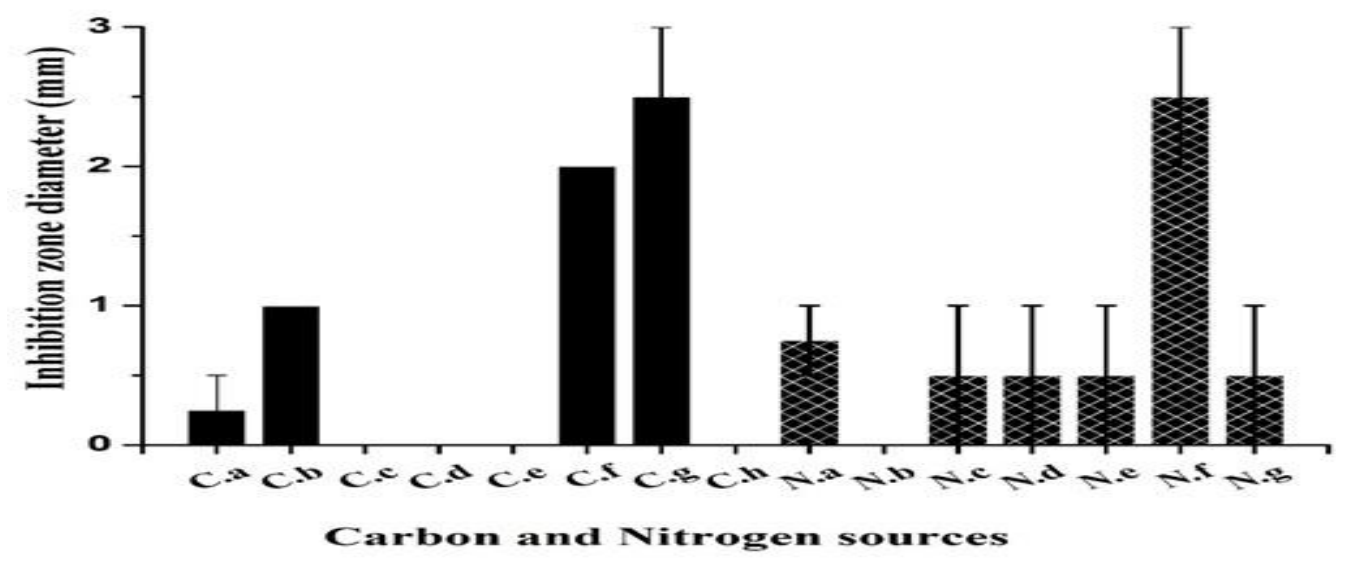

Fig.6 TLC crude extract study. (A) Antimicrobial of crude extract on aluminum silica gel TLC plate and (B) Agar diffusion method of brown fraction of isolate Ru87 against S. aureus agar diffusion method. A total volume of $500 \mathrm{ml}$ starch casein broth media (pH7) was inoculated with spore suspension (1\%) of isolate Ru87. The fermentation process was carried out for 8 days at 30 -C under shaking conditions (150 RPM). Cell-free supernatant was filtrated through filter paper (Whatman) and extracted using chloroform-ethylacetate $(1: 1 \mathrm{v} / \mathrm{v})$ in a separating funnel (three times). The mixtures were then evaporated under vacuum until dryness in the rotatory evaporator at $37^{\circ} \mathrm{C}$. The crude residue was dissolved in $3 \mathrm{ml}$ ethyl acetate $0.2 \mathrm{ml}$ was loaded on aluminum silica gel TLC plate (Merck) with the use of chloroform: methanol (4:1 v/v) as mobile phase under saturated conditions for 1, 30 hour. Brown fraction was detected as shown by the arrow. The brown fraction is scratched from the TLC, eluted in $0.1 \mathrm{ml}$ DMSO and then $0.25 \mathrm{ml}$ was subjected to agar well diffusion method for antibiotic assays against $S$. aureus
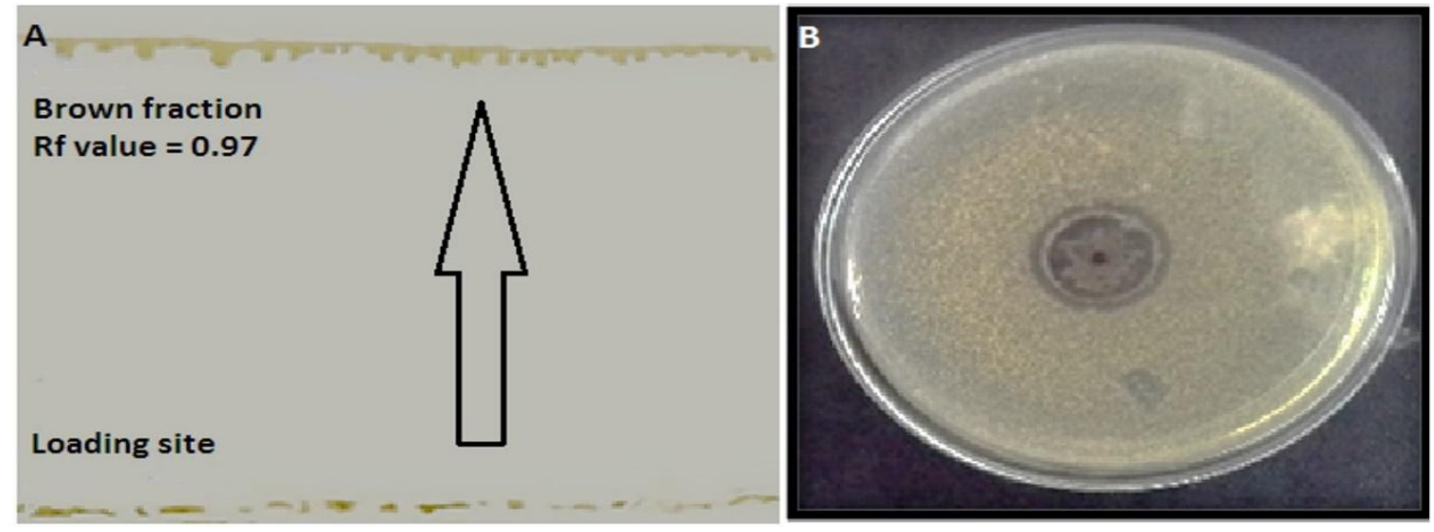
Fig.7 (A): LC-MS/MS of brown band of isolate Ru87 dissolved in DMSO, (B): HPLC of brown band of isolate Ru87 dissolved in DMSO. LC-MS/MS of brown band of isolate Ru87 dissolved in DMSO conducted in the Selected Ion Monitoring (SIR) mode. HPLC of brown band of isolate

Ru87 dissolved in DMSO conducted in the multiple reaction monitoring (MRM) mode

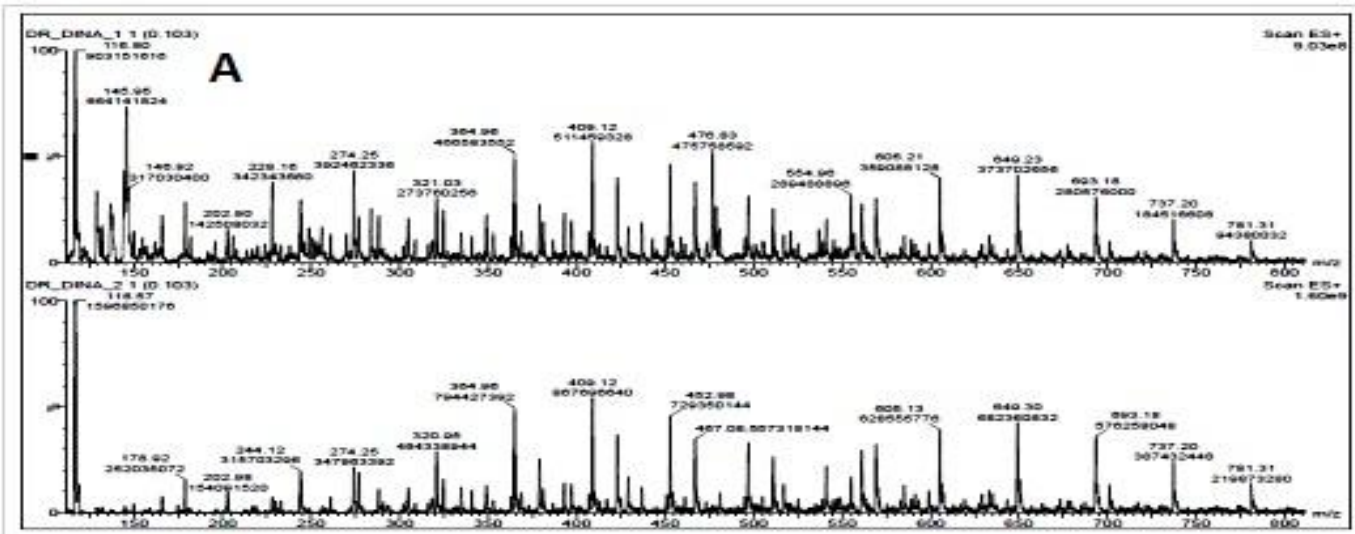

B

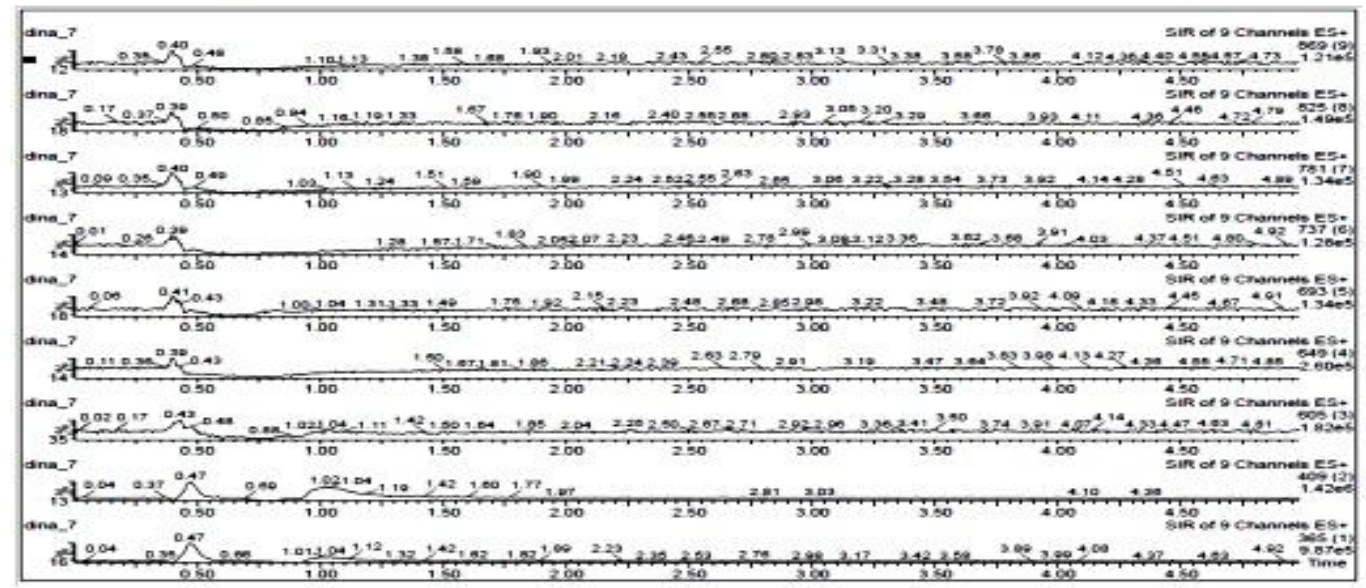

Fig.8 Mass spectrum of the brown band of isolate Ru87. The mass spectrum of the brown band eluted in methanol was determined by using mass spectrophotometer API 2000 (PE Sciex Applied Biosystems, Foster City, CA, USA)

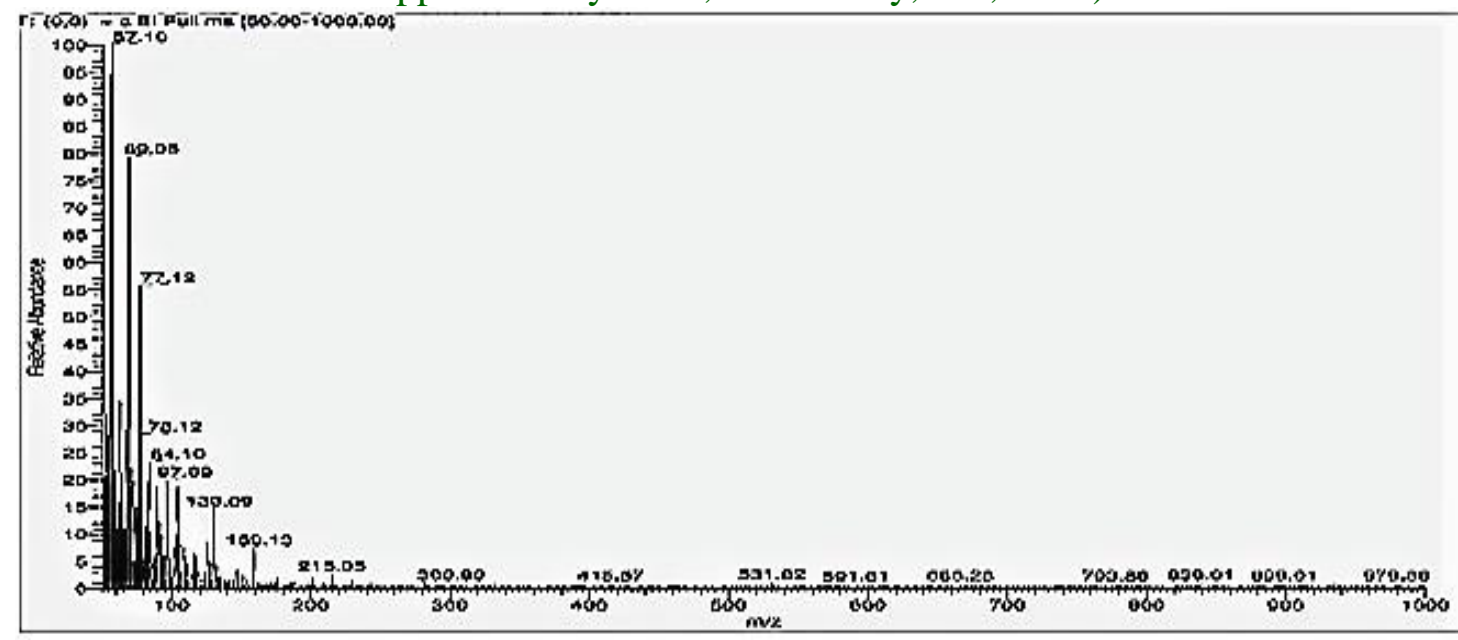


Fig.9 IR analysis of eluted brown fraction of isolate Ru87. It was recorded in DMSO using potassium bromide disks with Perkin-Elmer Infrared 127B Spectrophotometer

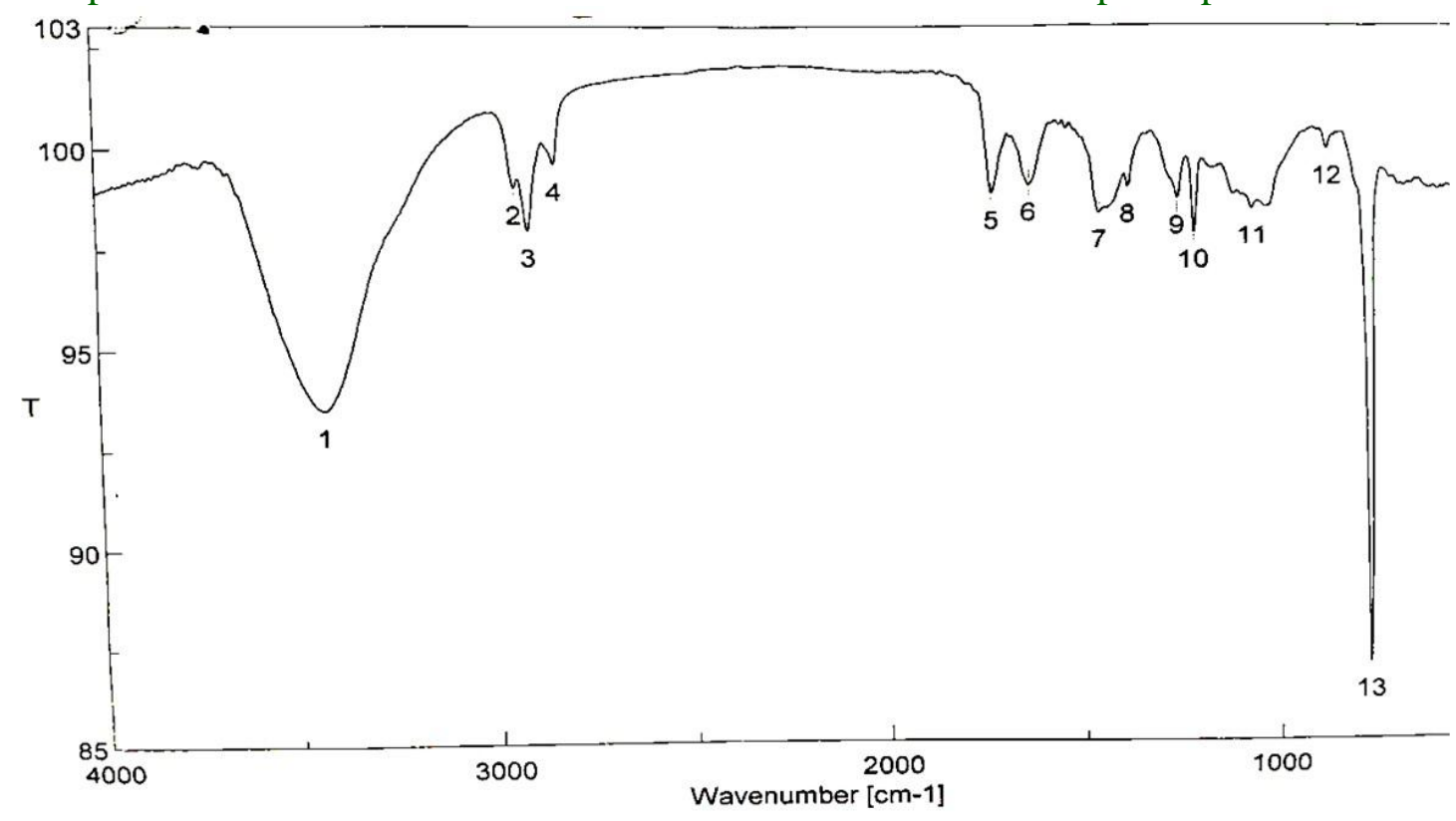

Fig.10 ${ }^{1} \mathrm{H}-\mathrm{NMR}$ of eluted brown fraction of isolate Ru87. Brown fraction of isolate Ru87 was recorded on a Varian 500 MHZ NMR spectrometer with tetra-methyl silane (TMS) as an internal standard

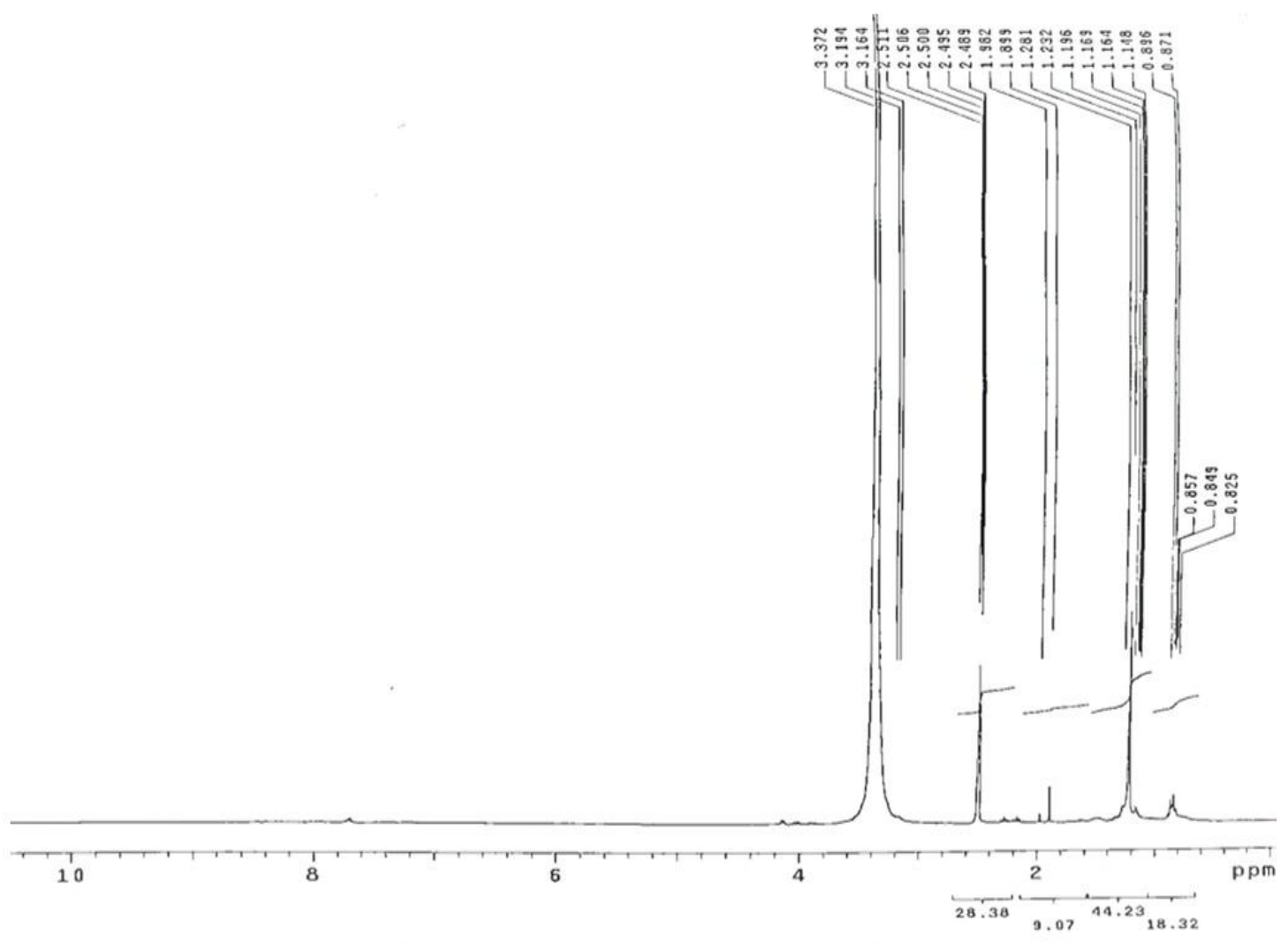


Fig.11 ${ }^{13} \mathrm{C}-\mathrm{NMR}$ of eluted brown fraction of isolate Ru87.Brown fraction of isolate Ru87 was recorded on a Varian 500 MHZ NMR spectrometer with tetra-methyl silane (TMS) as an internal standard

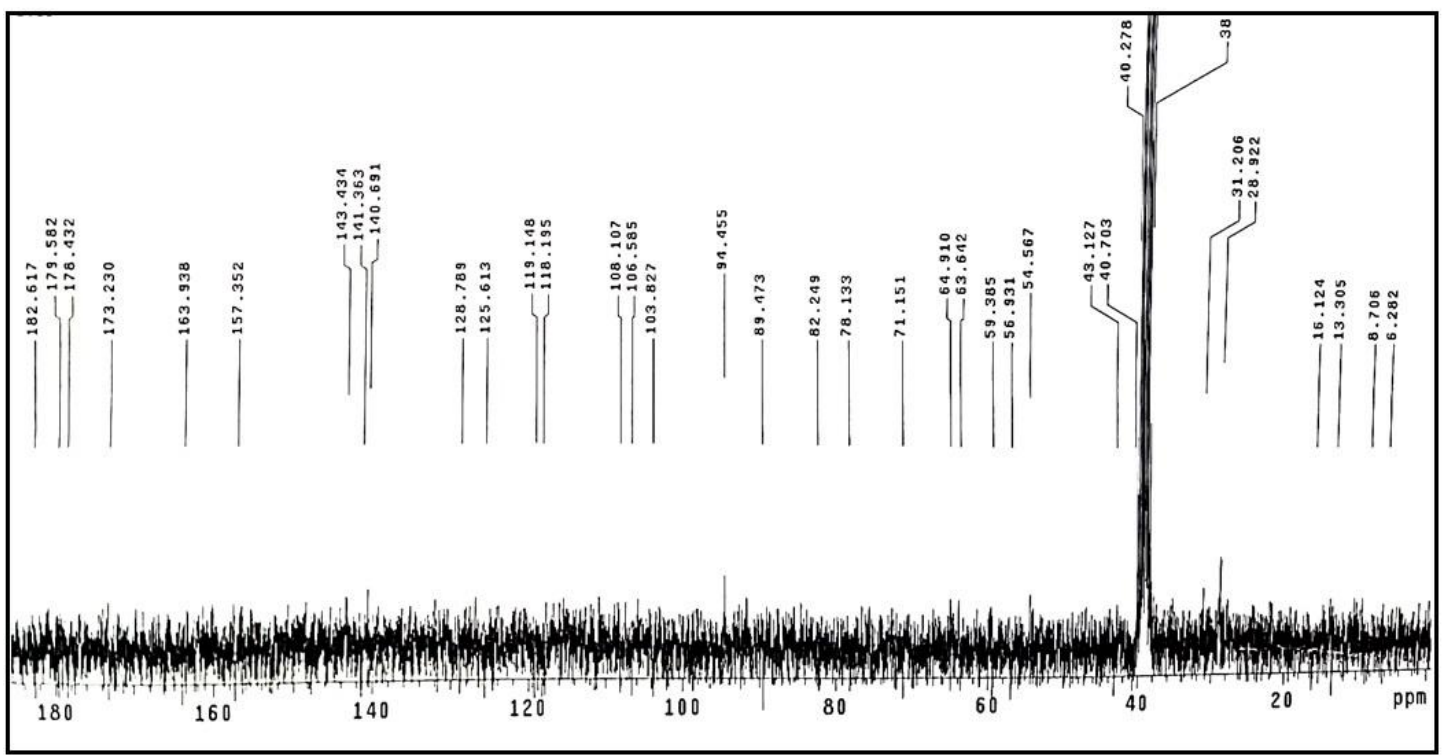

Fig.12 The Minimum inhibitory concentration (MIC) of purified active fraction of isolate Ru87 was detected using tube Dilution Assay against $S$. aureus. Different concentrations of purified active fraction eluted in $(0.3,0.6,0.9,1.5,3,6,12$ and 24) $\mu \mathrm{g} / \mathrm{ml}$ were each added to $5 \mathrm{ml}$ nutrient broth tubes, vortexed and then inoculated with equal amount $(10 \mu \mathrm{l})$ of overnight culture of S. aureus ATCC 6538 (O.D $600=0.164)$. Tubes were incubated at $37^{\circ} \mathrm{C}$ for $24 \mathrm{hrs}$ and the optical density of each tube was measured by spectrophotometer. The Minimum inhibitory concentration (MIC) was identified as the first concentration that appears to inhibit bacterial

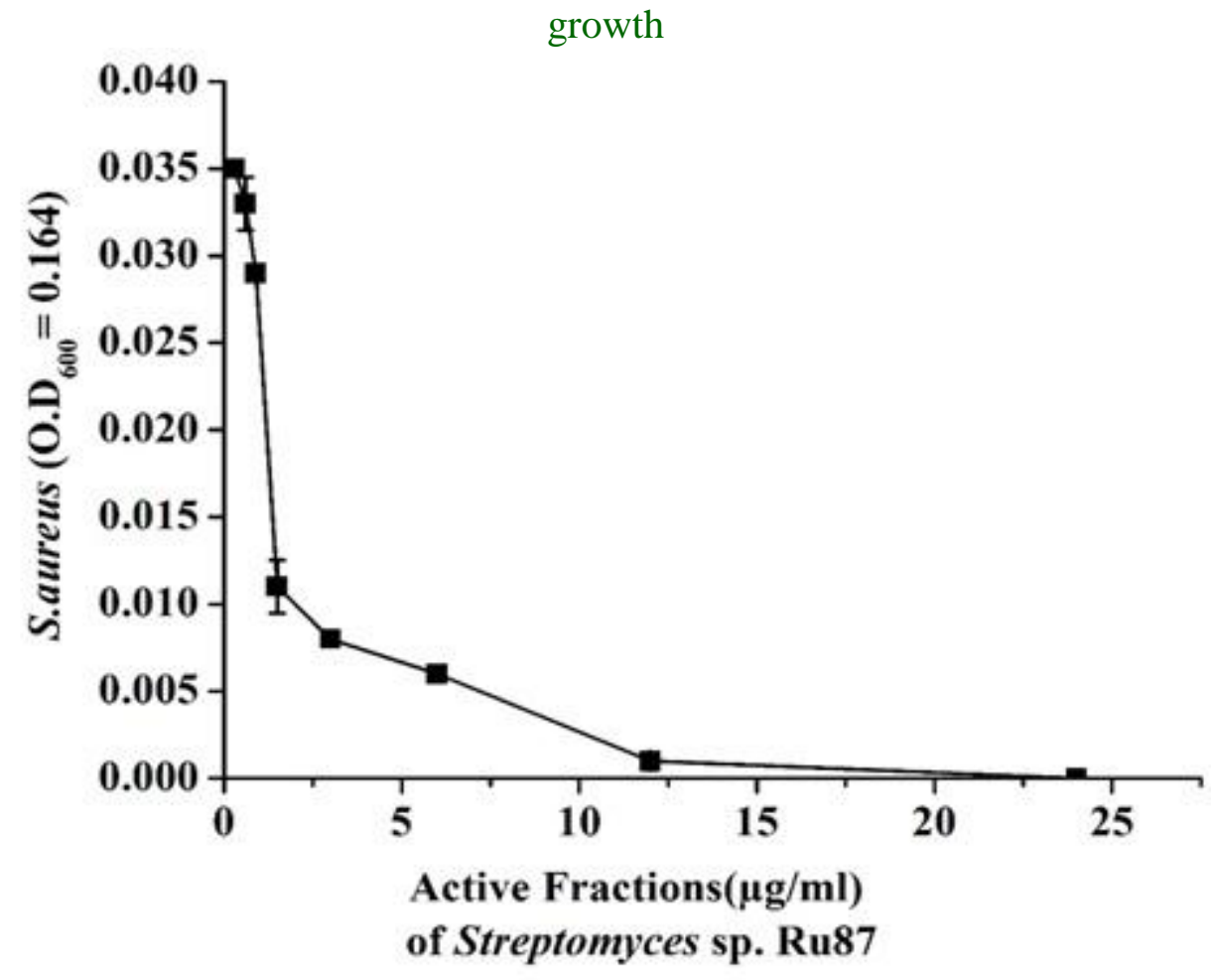




\section{Partial characterization of potential} antimicrobial compounds

Several components and derivatives are generated from antibiotic-producing Actinomycetes (Khanna et al., 2011). Thin Layer Chromatography (TLC) and High Performance Liquid Chromatography (HPLC) have been successfully used for the purification and characterization of such bioactive opponents (Khanna et al., 2011). TLC Purification of the extracted culture broth of Ru87 yielded one brown fraction with RF value of 0.97 .This fraction inevitably exhibited antimicrobial activities when assayed against $S$. aureus via agar well diffusion method (Fig. 6).

The molecular weight profile of antimicrobial fractions was obtained using LC mass scanning (Fig. 7. A).HPLC was then used for further identification for each fraction and showed same peak and same retention time (0.40) with all the scanned daughter ions molecular weights (Fig. 7.B). Inevitably, this confirmed the purification of one pure unique compound.

Mass spectroscopy chart showed that the antimicrobial compound has large Mwt (979) shown in (Fig.8). IR chromatogram showed that peaks1 and 2 of intensity (3745) and (3442) indicates the presence of amide I functional group, with more than $95 \%$ due to the $\mathrm{N}-\mathrm{H}$ stretching vibration. Amide I is the most intense absorption band in proteins. While, peak 8 of intensity (1636) indicates the presence of stretching vibrations of the $\mathrm{C}=\mathrm{O}$ (70-85\%) and C-N groups (10-20\%) (Fig.9). $\mathrm{NMR}(\mathrm{H}+)$ chart showed a signal at the position (7.8) that indicates the protons of the benzene ring and amide functional group. Results confirmed the aromatic structure of this compound (Fig.10). NMR $\left(\mathrm{C}^{13}\right)$ chart showed 3 confirmatory signals at positions $(157,163$ and 173) that indicate the carbon atoms in the amide functional group once appeared in the IR chart. While, the second signal at (128 and 125) that refer to the carbon of the benzene ring as shown in (Fig. 11). This result agrees with IR and NMR (H+) chart. The above measurements indicated that isolate $\mathrm{Ru} 87$ produces aromatic peptide compound.

\section{Minimum Inhibitory Concentration (MIC) of Bioactive Fraction}

A dramatic inhibition occurred when purified active fractions $(0.3,0.6,0.9,1.5,3,6,12$ and 24) $\mu \mathrm{g} / \mathrm{ml}$ were tested against $S$. aureus in Tube Dilution Assay (Fig. 12) followed by delicate descending pattern down to $12 \mu \mathrm{g}$ active fraction $/ \mathrm{ml}$. The Minimum inhibitory concentration (MIC) occurred at a concentration of $24 \mu \mathrm{g}$ active fraction $/ \mathrm{ml}$.

In our study, Streptomyces sp strain Ru87 was isolated from Egyptian soil and screened for its antimicrobial activities against some foodborne and blood borne pathogens. Staphylococcus aureus ATCC6538 showed significant high antimicrobial response, and therefore selected as model target for the entire study. Sequencing of partial 16S rDNA and BLASTN indicated that isolate Ru87 is identical to Streptomyces cacaoi (98\%). However the NJ phylogenetic tree showed low bootstrap value that means that it is a distinct species. Streptomyces cacaoi subsp. cacaoiAB184115 was isolated for the first time in 1932 by Waksman from cacao beans, and then Streptomyces cacaoi strain SU2 JF730119 from marine sediment (Nandhini and Selvam, 2011) and Streptomyces cacaoi subsp. cacaoi strain GU144523 from scalp (Pellegrini, 2012). This is the first record of Streptomyces cacaoi to be isolated from Egyptian soil by selective pretreatments on humic acid vitamin agar media with this comprehensive study of antimicrobial activity, phylogenetic analysis and chemical 
characteristic of antibiotics components. The optimum condition for highest yield of antimicrobial agent was obtained after 6 days of culturing $4 \times 10^{5} \mathrm{CFU} / \mathrm{ml}$ of Ru 87 in starch casein broth media with agitation (150 RPM) at $30^{\circ} \mathrm{C}, \mathrm{pH}$ 7.0. Similar values of optimum $\mathrm{pH} 7$ and 6-days of incubation periods were reported from Streptomyces isolates (AlZahrani, 2007; Rizk et al., 2007; Narayana and Vijayalakshmi, 2008; Thakur et al., 2009; Oskay, 2009; Abdelwahed et al., 2012). However, 10- 12-days of incubation were recorded to generate the highest yield of antimicrobial agents production by Streptomyces sp. RUPA-08PR (Ripa et al., 2009) and Streptomyces violatus (Hassan et al., 2001).Carbon and nitrogen sources were are essential components in the culture media. Maximum yield of antimicrobial agents was obtained when starch and casein was added to Ru87 culture media while glucose and yeast extract were the best choice for Streptomyces sp. isolates (Ripa et al., 2009; Abdelwahed et al., 2012) and maltose and soyabean for Streptomyces sp. 201 isolate (Narayana and Vijayalakshmi, 2008). Moreover, peptone and alanine recorded the highest antimicrobial productivity by Streptomyces sp. Isolated by Hassan et al., (2001), while sucrose and starch were the favorite carbon source for maximum antimicrobial yield obtained from Streptomyces sp. KGG32 (Oskay, 2011) and Streptomyces sp. DN37, respectively (Abdelwahed et al., 2012).

Furthermore, Chemical characteristics indicated that Streptomyces sp. Ru 87 produce antibiotics related to aromatic peptides, which was never been reported before with antibacterial activity against $S$. aureus ATCC 6538. In 1977, Koenuma and Otake had explored the chemical characteristics of antibiotics produced by Streptomyces cacaoivar. Asoensis reported Lysocellinas the type of antibiotic among the group of polyether antibiotic. Further investigations are definitely required to identify the complete structure of this molecule. In addition, genetic manipulation of the strain that will helps to increase the production ability. This can be a promising product to control microbial drug resistance in Egypt.

\section{Acknowledgment}

We would like to thank the Microbial Resources Center (Cairo MIRCEN) and Ain Shams Specialized Hospital for providing the strains of Foodborne and blood borne pathogens strains as a gift. We are very grateful for the Scholarship provided by Egyptian missions and British council in Egypt (Newton-Mosharafa program 20162017) to complete and conduct the Molecular studies at the School of Life Sciences, Lab C123, University of Warwick, UK. We would also like to thank the teamwork of AGERI center, Cairo, Egypt for conducting Liquid Chromatography-Mass Spectrometry (LCMS) and High Performance Liquid Chromatography (HPLC). Special greetings for Central Laboratory Services, National Research Centre in Cairo, Egyptwhere we had chemical characteristics using Mass Spectrophotometer API 2000, Infrared 127B Spectrophotometer, Varian 500 MHZ NMR spectrometer. We would like to recognize the Mycological center, Assiut University, Assiut, Egypt for preparing lyophilized final spore suspension.

\section{Conflict of interest}

We declare that we have no conflict of interest.

\section{References}

Abbas A., S., Edwards, C. (1990). Effects of metals on Streptomyces coelicolor growth and actinorhodin production. Appl. Environ. Microbiol, 56, 675-680.

Abd-allah, N., Tolba, S., Hatem, D. (2012). 
Selective isolation of rare actinomycetes from different types of Egyptian soil. Egypt J. Exp. Biol., 8(2), 175- 182.

Abdelwahed, N., A., Abdallah, N., A., ElGhawas, D., E., EL-Din, S., M., B., ElDiwany, A., I. (2012). Isolation, Identification and optimization of antimicrobial metabolites produced by soil derived actinomycetes. Egypt. J. Exp. Biol. (Bot.), 8(2), $205-217$.

Al-Zahrani, S., H. (2007). Studies on the antimicrobial activity of Streptomyces sp. isolated from Jazan. Science, 19(1).

Bérdy, J. (2012). Thoughts and facts about antibiotics: where we are now and where we are heading. The Journal of antibiotics, 65(8), 385-395.

Cooper, K., E. (1972). In F. Kavanagh (ed.), Analytical Microbiology, Vol. 2, 13-30, Academic Press, New York.

Edwards, U., Rogall, T., Blocker, H., Emde, M., Bottger, E. (1989). Isolation and complete nucleotide determination of entire genes. Characterization of a gene coding for $16 \mathrm{~S}$ ribosomal RNA. Nucleic Acids Res., 17, 7843-7853.

El Kholy, A., Baseem,H., Hall, G., S., Procop, G.,W., Longworth, D., L. (2003). Antimicrobial resistance in Cairo, Egypt 1999-2000: a survey of five hospitalsJ Antimicrob Chemother.51 (3), 625-630.

Euzeby, J., P. (2008). Genus Streptomyces. List of Prokaryotic names with Standing in Nomenclature

http://www.bacterio.cict.fr/s/streptomycesa. html.

Falagas, M., E., Lourida, P., Poulikakos, P., Rafailidis, P., I., Tansarli, G., S. (2013). Antibiotic treatment of infections due to carbapenem-resistant Enterobacteriaceae: systematic evaluation of the available evidence. Antimicrobial agents and chemotherapy, AAC-01222.

Hassan, M., A., El-Naggar, M., Y., Said, W., Y. (2001). Physiological factors affecting the production of an antimicrobial substance by Streptomyces violatus in batch cultures. Egyptian Journal of Biology, 3(1), 1-10.

Hassan, A., M., Ibrahim, O., El Guinaidy, M. (2011).Surveillance of antibiotic use and resistance in Orthopaedic Department in an Egyptian University Hospital International Journal of Infection Control., Vol. 7 (1), 110.

Hayakawa, M., Nonomura, H. (1987).Humic acidvitamin agar, a new medium for the selective isolation of soil actinomycetes. J. Ferment. Technol., 65, 501-509.

Heuer, H., Krsek, M., Baker, P., Smalla, K. Wellington, E., M., H. (1997). Analysis of actinomycete communities by specific amplification of genes encoding 16S rRNA and gel electrophoretic separation in denaturing gradients. Appl. Environ. Microbiol, 63 (8), 3233-3241.

Hilal, S., El Kholy, A., El Ansary, M., El Rachidi, N. (1997). Comparison of a polymerase chain reaction (PCR) assay and standard susceptibility testing methods for detection of methicillin resistant Staphylococcus aureus. Journal of Cairo University, 65, 6777.

Hopwood, D., A., Bill, M., J., Charter, K., F., Kieser, T., Bruton, C., J., Kieser, H., M., Lydiate, D., J., Smith, C., P., Ward, J., M., Schrempf, H. (1985). Genetic manipulation of Streptomycetes: A laboratory manual, John Innes Foundation, Norwich, United Kingdom, pp: 71- 80.

Khanna, M., Solanki, R., Lal, R. (2011). Selective isolation of rare actinomycetes producing novel antimicrobial compounds. Int $J$ AdvBiotechnol Res, 2(3), 357-75.

Kieser, T., Bibb, M., J., Buttner, M., J., Chater, K., F., Hopwood, D., A. (2000). Practical Streptomyces Genetic John Innes Foundation, Norwich, England, ISBN 07084-0623.

Koenuma, M., Otake, N. (1977). Studies on the Ionophorous antibiotics. XI. The artifacts and the degradation products of lysocellin. The Journal of antibiotics, 30 (10), 819828 .

Korzeniowski, O., Sande, M. A. (1982). Combination antimicrobial therapy for Staphylococcus aureus endocarditis in patients addicted to parenteral drugs and in non addicts: a prospective study, Annals of Internal Medicine, 97(4), 496-503.

Krimm, S., Bandekar, J. (1986). Vibrational spectroscopy and conformation of peptides, 
polypeptides, and proteins. Advances in protein chemistry, 38, 181-364.

Laxminarayan, R., Duse, A., Wattal, C., Zaidi, A., K., M., Wertheim, H., F., L., Sumpradit, N., Vlieghe, E., Hara, G., L., Gould, I., M., Goossens, H., Greko, C., So, A., D., Bigdeli, M., Tomson, G., Woodhouse, W., Ombaka, E., Peralta, A., Q., Qamar, F., N., Mir, F., Kariuki, S., Bhutta, Z., A. (2013). Antibiotic resistance - the need for global solutions.The Lancet Infectious Diseases. 13, (12), 1057-1098.

Locci, R. (1989).Streptomyces and related Genera. Bergey's Manual of Systematic Bacteriology. Williams \& Wilkins Company, Baltimore, 4, 2451-2508.

Madigan, M., Martinko, J., 2005.Brock Biology of Microorganisms.11th Edn, Prentice Hall, New Jersy, USA.

McFarland, J. (1907). The nephelometer: an instrument for estimating the number of bacteria in suspensions used for calculating the opsonic index and for vaccines. Journal of the American Medical Association, 49(14), 1176-1178.

Mellouli, L., Ameur-Mehdi, R., B., Sioud, S., Salem, M., Bejar, S. (2003). Isolation, purification and partial characterization of antibacterial activities produced by a newly isolated Streptomyces sp. US24 strain. Res. Microbiol. 154, 345-352.

Miyadoh, S. (1993). Research on Antibiotic Screening in Japan over the Last Decade: A Producing Microorganisms Approach. Actinomycetologica. 9, 100-106.

Monciardini, P., Sosio, M., Cavaletti, L., Chiocchini, C., Donadio, S. (2002). New PCR primers for the selective amplification of $16 \mathrm{~S}$ rDNA from different groups of actinomycetes. FEMS Microbiology Ecology, 42(3), 419-429.

Nandhini, S., U., Selvam, M., M. (2011). Antibacterial activity of the streptomycetes isolated from marine soil sample. In Green Technology and Environmental Conservation, 362-365.

Narayana, K., J., P., Vijayalakshimi, M. (2008). Optimization of antimicrobial metabolites production by Streptomyces albidoflavus, Res. J. Pharmacol., 2 (1)4-7.

Oskay, M. (2009). Antifungal and antibacterial compounds from Streptomyces strains. African Journal of Biotechnology, 8(13), 3007-3017.

Oskay, M. (2011). Effects of some environmental conditions on biomass and antimicrobial metabolite production by Streptomyces sp., KGG32. International Journal of Agriculture and Biology, 317-324.

Pellegrini, G., J. (2012). Scalp Abscess Due to Streptomyces cacaoisubspcacaoi, First Report in a Human Infection. Journal of clinical microbiology, 50(4), 1484-6.

Pfaller, M., A., Jones, R., N., Doern, G., V., Kugler, K., \& the Sentry Participant Group. (1998). Bacterial pathogens isolated from patients with bloodstream infection: frequencies of occurrence and antimicrobial susceptibility patterns from the SENTRY Antimicrobial Surveillance Program (United States and Canada). Antimicrobial Agents and Chemotherapy, 42, 1762-70.

Pridham, T., G., Lindenfelser, L., A., Shotwell, O., L., Stodola, F., Benedict, R., G., Foley, C., Mitchell, J., W. (1956). Antibiotics against plant disease. I. Laboratory and green house survey. Phytopathol, 46, 568575.

Provost, F., Laurent, F., Camachouzcategeri, L., R., Boiron, P. (1997). Molecular study of persistence of Nocardia asteroides and Nocardia otitidiscaviarum strains in patients with longterm nocardiosis. J ClinMicrobiol, 35, 1157-60.

Roller, K. (1999). "Experimental Staph Vaccine Broadly Protective in Animal Studies," National Institute of Allergy and Infectious Diseases, http://www.nih.gov/news/pr/may99/niaid27.htm.

Ripa, F., A., Nikkon, F., Zaman, S., Khondkar, P. (2009). Optimal conditions for antimicrobial metabolites production from a new Streptomyces sp. RUPA-08PR isolated from Bangladeshi soil. Mycobiology, 37(3), 211-214.

Rizk, M., Abdel-Rahman, T., Metwally, H. (2007). Factors affecting growth and antifungal activity of some Streptomyces species against Candida albicans. Journal of Food, agriculture and Environment, 5, $412-415$. 
Shirling, E. T., Gottlieb, D. (1966). Methods for characterization of Streptomyces species. International Journal of Systematic and Evolutionary Microbiology, 16(3), 313340.

Staneck, J., L., Roberts, G., D. (1974). Simplified approach to identification of aerobic actinomycetes by thin-layer chromatography. Applied microbiology, 28(2), 226-231.

Tamura, K., Peterson, D., Peterson, N., Stecher, G., Nei, M., Kumar, S. (2011). MEGA5: molecular evolutionary genetics analysis using maximum likelihood, evolutionary distance, and maximum parsimony methods. Mol. NRPS and PKS Diversity in Soils. BiolEvol. 28(10), 2731-9.

Thakur, D., Bora, T., C., Bordoloi, G., N., Mazumdar, S. (2009). Influence of nutrition and culturing conditions for optimum growth and antimicrobial metabolite production by Streptomyces sp. 201, Journal of Medical Mycology, 19(3), 161167.

Thompson, J. D., Higgins, D. G., Gibson, T. J. (1994). CLUSTAL W: improving the sensitivity of progressive multiple sequence alignment through sequence weighting, position-specific gap penalties and weight matrix choice. Nucleic acids research, 22(22), 4673-4680.

Tiwari, K., Gupta, R. K. (2012). Rare actinomycetes: a potential storehouse for novel antibiotics. Critical reviews in biotechnology, 32(2), 108-132.

Waksman, S. A., Schatz, A. (1945). Strain specificity and production of antibiotic substances. I V. Variations among actinomycetes, with special reference to Actinomyces griseus. Proc. Nat. Acad. Sci., 31, 129-137.

Watve, M., G., Tickoo, R., Jog, M., M., Bhole, B., D. (2001). How many antibiotics are produced by the genus Streptomyces. Arch Microbiol, 176, 386-390?

Wiegand, I., Hilpert, K., Hancock, R., E. (2008). Agar and broth dilution methods to determine the minimal inhibitory concentration (MIC) of antimicrobial substances. Nature protocols, 3(2), 163175.

Williams, S., T., Davies, F., L. (1965). Use of antibiotics for selective isolation and enumeration of actinomycetes from soil. Journal of General Microbiology, 38, 251261.

Williams, S., T., Sharpe, M. E., Holt, J. G. (1989). Bergey's manual of systematic bacteriology, Vol 4. Williams and Wilkins, London. ISBN 0-68309-061-5.

Yamamura, H., Hayakawa, M., Iimura, Y. (2005). Application of sucrose-gradient centrifugation for selective isolation of Nocardia spp. from soil. International Journal of Systematic and Evolutionary Microbiology, 55(1), 433-436.

\section{How to cite this article:}

Dina H. Amin, Sahar Tolba, Assem Abolmaaty, Nagwa A. Abdallah and Elizabeth, Wellington, M.H. 2017. Phylogenetic and Antimicrobial Characteristics of a Novel Streptomyces sp. Ru87 Isolated from Egyptian Soil. Int.J.Curr.Microbiol.App.Sci. 6(8): 25242541. doi: https://doi.org/10.20546/ijcmas.2017.608.299 